\title{
Monitoring and Rationalizing Energy Consumption of Home Electric Appliances
}

\author{
Khairy Sayed ${ }^{1}$, Farid Naguib Abdelbar ${ }^{2}$, Emad Elzohri $^{3}$, Allam Ahmed ${ }^{4}$ \\ Faculty of Engineering, Sohag University, Sohag, Egypt ${ }^{1}$ \\ Faculty of Engineering, Assiut University, Assiut, Egypt ${ }^{2}$ \\ Faculty of Technology and Education, Sohag University, Sohag, Egypt ${ }^{3}$ \\ Student, Electrical Department, Faculty of Industrial Education, Sohag University ${ }^{4}$
}

\begin{abstract}
There are several solutions exist to save energy consumption in residential, commercial and industrial buildings. This paper presents a new model device to monitor the consumption of energy consumed in homes to rationalize energy consumption using a wireless meter using Arduino controller. The controller calculates the actual energy consumption at any moment and sends it to the computer using Wi-Fi module. The energy is digitally measured using Arduino and displayed graphically. An energy saving plan is proposed to save energy in residential loads. The recorded results are filtered to rationalize the consumption of energy to the extent required. To evaluate the performance of the proposed system, an experimental setup is conducted on residential apartments and rationalizing the consumption of electric energy by reducing the load without prejudice to the normal state of loads. The rate of rationalization in electric power is reached $25 \%$ of the value of total consumption. Therefore, the goal of controlling consumption and rationalization is achieved accurately and at the lowest cost possible and using advanced electronic elements to eliminate the inaccuracy in reading the meter home.
\end{abstract}

Keywords: Energy meter; arduino based energy meter, electricity consumption, energy saving

\section{I.INTRODUCTION}

Multiple ways to rationalize energy consumption from one place to another, Technologies are just now being developed that encourage sustainable energy usage in the home, give home residents feedback of their energy consumption, typically presented using a computer visualization. The expectation is that this feedback will motivate home residents to change their energy behaviors in positive ways [1]. A new wireless sensor network solution that can be used to profile power consumption of both electric power connected devices. This offers a better and easier way to monitor the energy each of the target devices, and get real time feedback on the effect of different usage patterns applied to target devices [2]. Energy monitoring system provides residential consumers with real time information about their electricity use. The system uses wireless communication and displays the information on a small LCD screen and on a computer, It uses primary models in the rationalization of electricity consumption.[3]Of modern technologies using Arduino, it has been developed a measure device, based on Arduino, which monitors the power consumption from each home device and sends this information to a server, On the other hand, users can see by means of their mobile devices the power consumption in real time.[4] Of the modern technologies used in the measurement of electrical power programmable controllers (Arduino) because of its many advantages to reduce the reduction of electricity . [5] To solve the problem of energy consumption, most researchers sought to provide energy consumption using home networking technologies to integrate home applications. A broad and inclusive home communication interface is analysed utilizing as a key piece a Gateway based on machine-to-machine (M2M) communications that interacts with the surrounding environment. Then, the main wireless networks are thoroughly assessed, and later, their suitability to the requirements of ( HAN). [6] ZigBee/Wi-Fi technology is a wireless device to monitor the intelligent system of electrical facilities with transmitter and receiver, able to detect absorbed current from electrical loads, to calculate dissipated power and energy by means of PIC-based software and to view, in real-time, calculated consumption values on web page properly realized for user's remote control.[7]There is another type of with ZigBee/WiFi transceivers, able to detect absorbed current from electrical loads, to calculate dissipated power and energy by means of PIC based software and to view the calculated consumption values on web page properly realized for user's remote control.[8] ZigBee technology was also used with RF technology, Real time energy data is acquired and transmitted through a RF link to a wireless terminal unit, which works as a data logger and as a human-machine interface. [9] Because electricity is one of the basic requirements in life 


\title{
International Journal of Innovative Research in Electrical, Electronics, Instrumentation and Control Engineering
}

\author{
Vol. 8, Issue 11, November 2020
}

\section{DOI 10.17148/IJIREEICE.2020.81101}

and with the advent of Internet and the web server, the systems of monitoring the consumption of electricity using modern technologies and linking them to Internet networks have been developed using the IOT system, which has the ability to transmit data over the Internet without the interaction of one [10]. Other technologies used with Arduino in monitoring power consumption are the IP communication system, the Internet connection and the remote control of equipment and devices using the intelligent application-based robot. The advantages of this system are that it does not rely on a server computer and uses mobile phones to control the home remotely [11]. Another modern technology used in energy consumption monitoring is the system that uses the Arduino and Bluetooth technology based on mobile phone and SMS for energy consumption [12]. Various techniques were used to monitor the consumption of electric energy to reduce energy consumption for consumers, including the use of SEM technology, a smart energy meter to reduce loads in peak hours [13] The latest in the world of electrical power consumption is to make the electrical appliances smart and provide convenience to the consumer and control the use of the Internet in the event of any manipulation of energy and power cuts automatically without reference to the consumer [14]. From previous studies, it is based primarily on monitoring only and using multiple techniques without reference to the consumer and the extent of the need to control whether or not to provide consumption for electricity companies and protect existing systems by introducing modern technologies on them. In the current system of electricity production and distribution companies, consumers are notified of the consumption rate once a month through the monthly bill and the length of this period affects the possibility of rationalizing electricity consumption. Moreover, the monthly invoice is insufficient to explain how the daily consumption of the user $[15,16]$.

The digital display of household electricity consumption was developed in measuring devices to display digital and graphical consumption of quantity and value of consumption, which led to the reduction of domestic consumption of electricity by $10-20 \%[17,18]$. Automation or automation of the home is defined as a high level of living by many smart home appliances that use control technology, computer technology and communication technology to provide the user with an advanced standard of living and safety. One of the most important benefits of home automation is the energy control system as an effective way to control and rationalize domestic consumption of electricity by using smart devices $[19,20]$. The mini-model was implemented as a wireless meter to measure the electrical power consumed in the home, which depends on the control of the Arduino micro-controllers, which is characterized by the speed of performance and accuracy in the results. [21]

Due to the outstanding research progress in the area of the smart grid, and renewable energy, power electronics industries have gained a great interest. Energy storage systems (ESS) such as batteries and supercapacitors have an important role in ensuring continuous power supply for the most critical electric loads, This contributes greatly to the advantage in the rationalization of energy using modern electronic devices, which consumes less energy in operation, [22-28] The reader consists of a current transformer to measure the current value of the consumer current, The Arduino controller, the wireless communication panel, and the computer. The software of the model is located in the control panel and also in the computer connected to the controller, which is the graphical user interface, which is used to display the data for the home use of the Electrical power to know the value of consumption at any moment. [29:31] In this paper, a new technology was introduced to help consumers monitor and rationalize household electricity consumption. In order to keep abreast of the evolution in monitoring and rationalizing the consumption of electric energy, this circuit was designed using the Arduino, the Wi-Fi network and the program of calculating the total capacity and display on the computer in order to know consumption at any moment and know the household loads that affect the increase in electricity consumption and work to eliminate Increase by reducing this consumption and knowing the value of total consumption and required to be paid according to the tariffs in the Arab Republic of Egypt.

\section{II.PROPOSED METER}

In this model, a wireless meter has been designed and implemented to measure the electrical power consumed in the home, which depends on the control of the Arduino, which is characterized by speed of performance and accuracy in the results. The reader consists of a current transformer to measure the value of the consumed current and control panel Arduino and the wireless communication panel in addition to the computer, and the software of this study in the control panel Arduino and also in the computer that is connected to the controller, which is the graphical user interface, which is used to display data of electrical power home user shown in Fig. 1.

The current through the main connectors in the main feeder panel of the home is measured by the Arduino controller. These values are sent as a UDP packet through the wireless network to the computer. The software installed in the computer analyzes these packets and converts the analog values to digital so that the current values and the knowledge of the electrical capacity consumed to be presented to the user. Therefore, the idea of working the model can be summed up in the measurement and aggregation of the values of the household current consumed accurately and at a rapid rate of update of these values and then these values are sent to the computer to display the values of electric power Consuming 


\section{International Journal of Innovative Research in Electrical, Electronics, Instrumentation and Control Engineering}

Vol. 8, Issue 11, November 2020

DOI 10.17148/IJIREEICE.2020.81101

the user, Figure 1 illustrates the overall design of the circuit and connect the circuit with the loads of Electrical and household items.

In order to maintain the user's safety and ease of installation, the measuring circuit is connected so that it is not connected in parallel with the main power lines in a way that does not require separation of the power lines for any reason. The wireless communication panel used in the model has the possibility of connecting to the home wireless network and the data rate of this wireless network Sufficient to support the required data refresh rate.

Figure 2 illustrates the Smart-home energy model with different load models for optimization and scheduling: An overview. The following forms show the drawings and charts of the model followed by the details of the components and their characteristics, Figures 3 and 4 show the block diagram of the system.

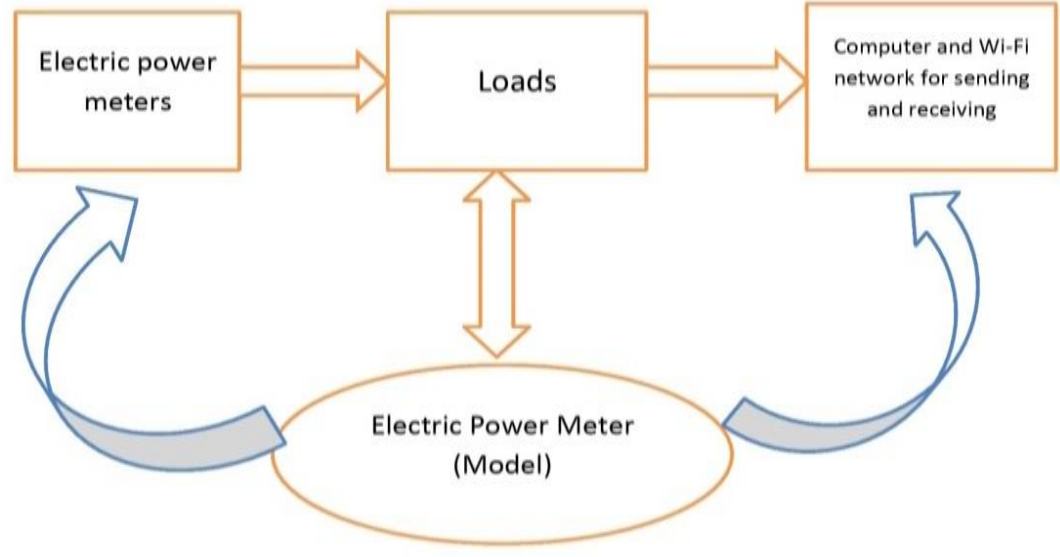

Figure 1 A simple illustration of the system model

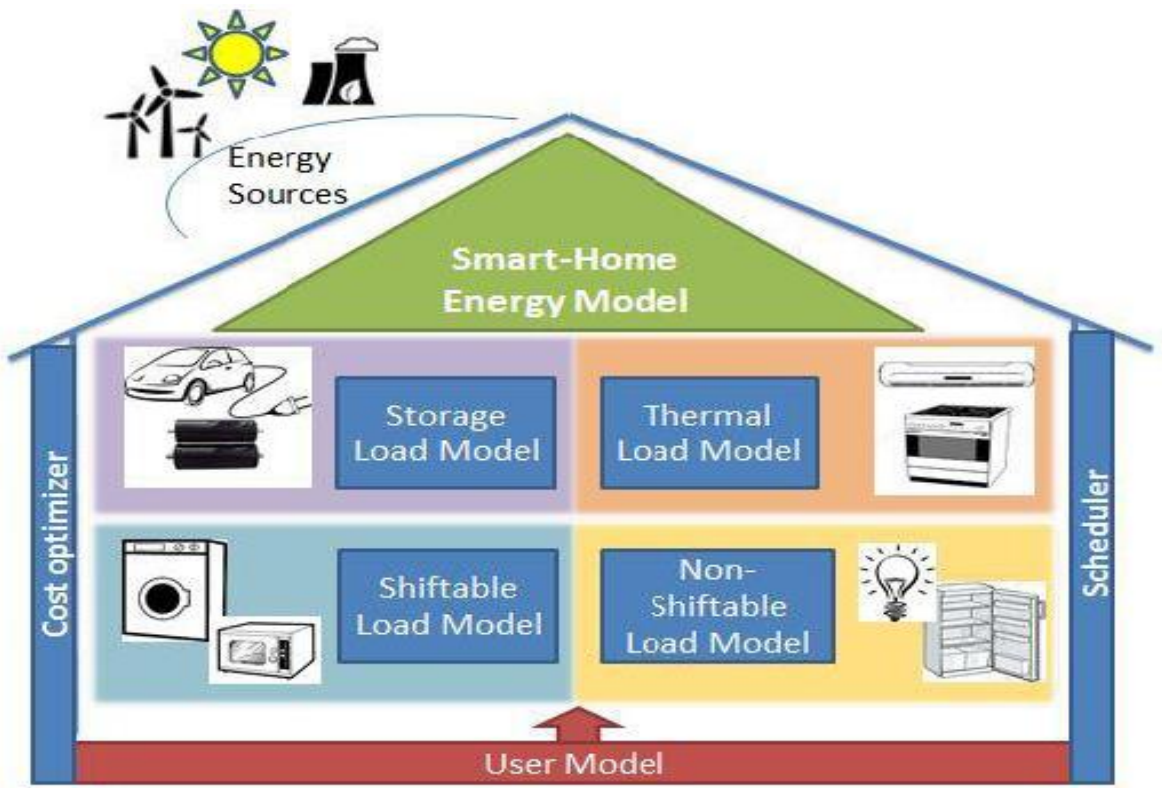

Figure 2 Smart-home energy model with different load models for optimization and scheduling: An overview 
International Journal of Innovative Research in Electrical, Electronics, Instrumentation and Control Engineering

Vol. 8, Issue 11, November 2020

DOI 10.17148/IJIREEICE.2020.81101

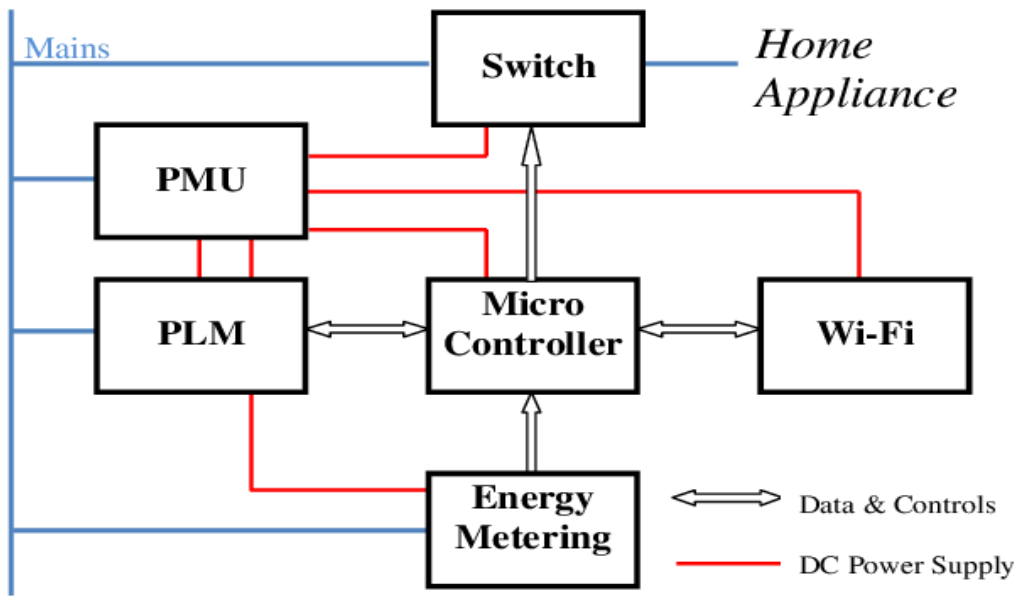

Figure 3 A block diagram of the port system
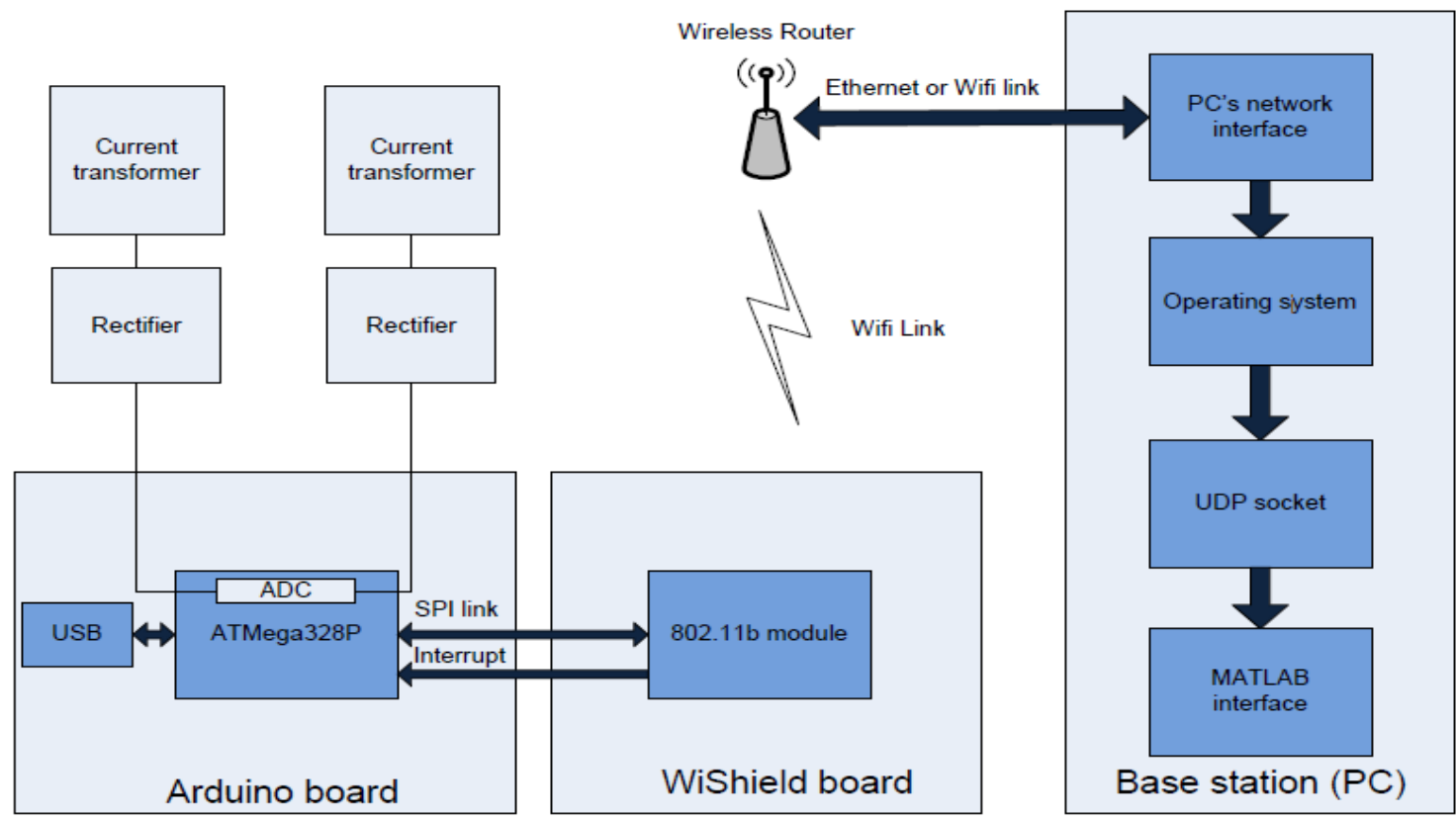

Figure 4 full System diagram

\section{III.SYSTEM IMPLEMENTATION}

Arduino is an electronic development board consisting of an open-source electronic circuit with a microcontroller on a single board programmed by computer and designed to make the use of interactive electronics in interdisciplinary projects easier. Arduino is used primarily in Design of interactive electronic projects or projects aimed at building different environmental sensors (eg temperature, wind, pressure, etc.). Arduino can be connected to various programs on the PC. Arduino's programming code is based on the open-source scripting language, and its special programming code is similar to $\mathrm{C}++$ programming language. It is one of the easiest programming languages used in microcontroller programming. Arduino Uno boards for the experimental circuits are easy to deal with, cheaper and compatible with most extensions and Shields.

Arduino Mega 2560 For the final circuits of the project to increase the number of input and outputs. It depends on the ATmega2560 controller. The following table shows the specifications for each of the two types Table 1. 
International Journal of Innovative Research in Electrical, Electronics, Instrumentation and Control Engineering

Vol. 8, Issue 11, November 2020

DOI 10.17148/IJIREEICE.2020.81101

Table 1 Data extracted from the two types circuits

\begin{tabular}{|c|c|c|c|c|c|c|c|c|c|c|}
\hline \multirow[t]{2}{*}{$\mathrm{m}$} & \multirow[b]{2}{*}{ Name } & \multirow{2}{*}{ 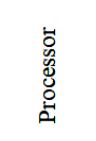 } & \multirow{2}{*}{$\begin{array}{l}\text { Operating } \\
\text { Voltage }\end{array}$} & \multirow{2}{*}{$\begin{array}{l}\text { CPU } \\
\text { Speed }\end{array}$} & \multirow{2}{*}{$\begin{array}{l}\text { Analog In/ } \\
\text { Out }\end{array}$} & Digital & \multirow{2}{*}{$\begin{array}{l}\sum_{2} \\
0 \\
\text { 空 } \\
\text { 䎡 }\end{array}$} & SRAM & Flash & \multirow{2}{*}{ 总 } \\
\hline & & & & & & IO/ PWM & & (KB) & (KB) & \\
\hline 1 & Uno & $\begin{array}{c}\text { ATmeg } \\
\text { a328 }\end{array}$ & $5 \mathrm{~V} / 7-12 \mathrm{~V}$ & $16 \mathrm{MHz}$ & Jun-00 & $14 / 6$ & 1 & 2 & 32 & 1 \\
\hline \multirow{2}{*}{2} & $\begin{array}{l}\text { Mega } \\
2560\end{array}$ & $\begin{array}{c}\text { ATmeg } \\
\text { a2560 }\end{array}$ & $5 \mathrm{~V} / 7-12 \mathrm{~V}$ & $16 \mathrm{MHz}$ & $16 / 0$ & $54 / 15$ & 4 & 8 & 256 & 4 \\
\hline & $\begin{array}{l}\text { Mega } \\
\mathrm{ADK}\end{array}$ & $\begin{array}{c}\text { ATmeg } \\
\text { a2560 }\end{array}$ & $5 \mathrm{~V} / 7-12 \mathrm{~V}$ & $16 \mathrm{MHz}$ & $16 / 0$ & $54 / 15$ & 4 & 8 & 256 & 4 \\
\hline
\end{tabular}

\section{A. Components of electrical power measurement circuit}

Themeasuremnet circuit consists of Arduino Uno(ATmega328) and Node Esp8266. The Smart Connectivity Platform (ESCP) is a set of high performance, high integration wireless SOCs, designed for space and power constrained mobile platform designers. It provides unsurpassed ability to embed WiFi capabilities within other systems, or to function as a standalone application, with the lowest cost, and minimal space requirement.

Smart Connectivity Platform (ESCP) demonstrates sophisticated system-level features include fast sleep/wake context switching for energy-efficient VoIP, adaptive radio biasing for low-power operation, advance signal processing, and spur cancellation and radio co-existence features for common cellular, Bluetooth, DDR, LVDS, LCD interference mitigation.

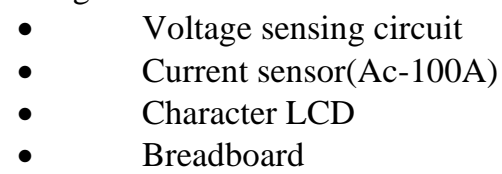

\section{B. Components of the transmitter and receiver circuit in the $\mathrm{Wi}-\mathrm{Fi}$}

The main element of the circle is the Esp8266 . Piece is suitable for all cards Alardoino UNO, MEGA, Leonardo, DUE Figure 5 shows the block diagram for Esp8266.

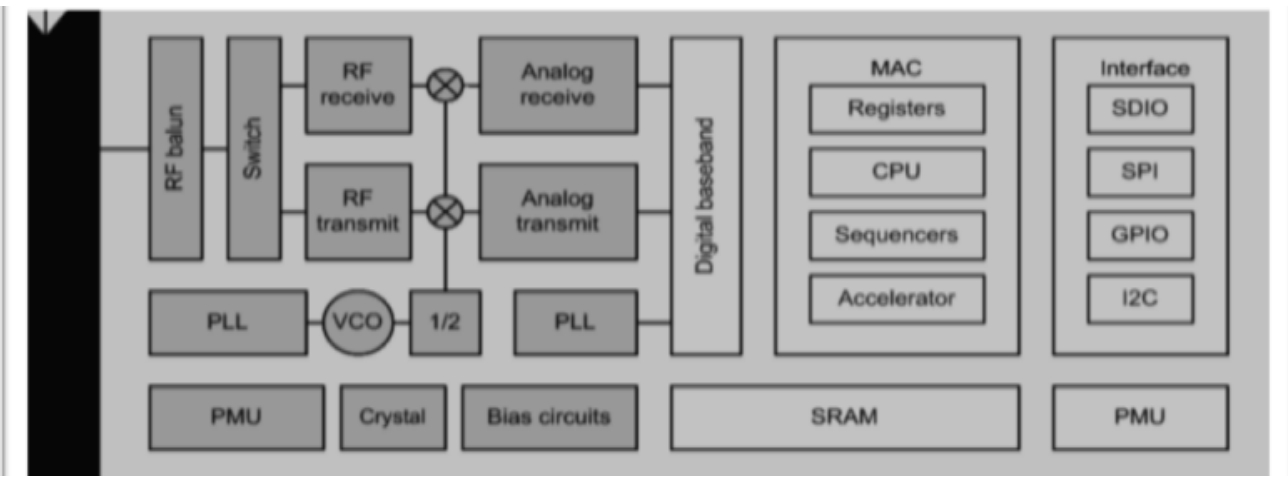

Figure 5 ESP8266EX Block Diagram

\section{Software used}

-Electronic circuit simulation programs

- program programming Arduino

- Capacity data processing program

- Electrical power calculation and consumption calculation program

- Arduino Software (IDE)

Software programs, called sketches, are created on a computer using the Arduino integrated development environment (IDE). The IDE enables you to write and edit code and convert this code into instructions that Arduino hardware understands. The IDE also transfers those instructions to the Arduino board (a process called uploading). 


\section{International Journal of Innovative Research in Electrical, Electronics, Instrumentation and Control Engineering}

Vol. 8, Issue 11, November 2020

DOI 10.17148/IJIREEICE.2020.81101

-Proteus Design suite 8.5

Proteus combines ease of use with powerful features to help you design, test and layout professional PCBs like never before. With nearly 800 microcontroller variants ready for simulation straight from the schematic, one of the most intuitive professional PCB layout packages on the market and a world class shape based auto-router included as standard, Proteus Design Suite 8 delivers the complete software package for today and tomorrow's engineers.

- MATLAB

is a multi-paradigm numerical computing environment and proprietary programming language developed by Math Works. MATLAB allows matrix manipulations, plotting of functions and data, implementation of algorithms, creation of user interfaces, and interfacing with programs written in other languages, including C, C++, C\#, Java, Fortran and Python.

4.1.5 Additions:-

- One-way electric counter 220 volts

- $\quad$ Protection circuits for electronic circuits

- Personal computer

- $\quad$ Router we use the following type because it is the average price and available in many markets TP-Link TD-

W8968

\section{D. $\mathbf{k W h}$ calculations}

For AC systems voltage and current pulsate at the system frequency. Although AC voltage and current pulsate at same frequency, they peak at different time power is the algebraic product of voltage and current. Real power is the average of power over cycle and measured by volt-amperes or watt. The portion of power with zero average value called reactive power measured in volt-amperes reactive or vars.

The total power is called the apparent power (symbolized by the capital letter S) and measured by volt-amperes or VA. To describe the reactive power, imagine a person on trampoline, The person real power goes into moving horizontally across trampoline as it bounces, the effort the person expend to keep standing (represent reactive power Q ) during bouncing result no net forward motion(represent real power $\mathrm{P}$ ), but it's necessary to walk on trampoline . The motion from trampoline always perpendicular to the direction the person is walking. So that the direction between $\mathrm{P}$ and $\mathrm{Q} 90$ degree Out of phase.

\section{Reactive power}

The reactive power is defined in the IEEE Standard Dictionary 100-1996 under the energy "magner" as:

Reactive power $=\sum_{\mathrm{n}=1}^{\infty} \mathrm{Vn} \cdot \operatorname{In} \cdot \sin (\varphi \mathrm{n})$

where $\mathrm{Vn}$ and In are respectively the voltage and current rms values of the nth harmonics of the line frequency and is the phase difference between the voltage and the current nth harmonics.

A convention is also adopted stating that the reactive energy should be positive when the current is leading the voltage (inductive load). In an electrical system containing purely sinusoidal voltage and current waveforms at a fixed frequency, the measurement of reactive power is easy and can be accomplished using several methods without errors. However, in the presence of non-sinusoidal waveforms, the energy contained in the harmonics causes measurement errors.

According to the Fourier theorem any periodic waveform can be written as a sum of sin and cosine waves. As energy meters deal with periodic signals at the line frequency both current and voltage inputs of a single phase meter can be described by:

$V(t)=\sum_{n=1}^{\infty} \mathbf{V n} \cdot \sqrt{2} \cdot \sin \llbracket(\mathbf{n} \boldsymbol{\omega} \mathbf{o t} \rrbracket) i(t)=\sum_{n=1}^{\infty} \mathbf{I n} \cdot \sqrt{2} \cdot \sin \llbracket(\mathbf{n} \boldsymbol{\omega} \mathbf{o t} \rrbracket+\boldsymbol{\varphi n})$ 


\section{International Journal of Innovative Research in Electrical, Electronics, Instrumentation and Control Engineering}

Vol. 8, Issue 11, November 2020

DOI 10.17148/IJIREEICE.2020.81101

where $\mathrm{Vn}$ and In are defined as in Equation 1.

Active power

The average active power is defined as:

Average active power $=\sum_{n=1}^{\infty}$ Vn.In. $\cos (\varphi n)$

The implementation of the active power measurement is relatively easy and is done accurately in most energy meters in the field.

\section{Apparent power}

The apparent power is the maximum real power that can be delivered to a load. As Vrms and Irms are the effective voltage and current delivered to the load,

Apparent power $=\mathrm{V}_{\mathrm{rms}} \bullet \mathrm{I}_{\mathrm{rms}}$

The correct implementation of the apparent energy measurement is bound by the accuracy of the rms measurements.

\section{Reactive power calculation}

Different methods can be used to calculate the reactive power. The theoretical definition of the reactive power is difficult to implement in an electronic system at a reasonable cost. It requires a dedicated DSP to process the Hilbert transform necessary to get a constant phase shift of $90^{\circ}$ at each frequency. Several solutions have been developed to overcome this limitation. They can be categorized in three groups:

\section{Method 1: Power triangle}

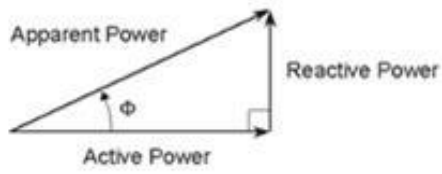

The Power triangle method is based on the assumption that the three energies, apparent, active and reactive, form a right-angle triangle as shown in Figure 1.11.

The reactive power :

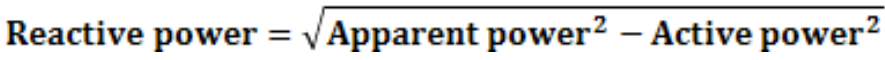

can then be processed by estimating the active and apparent energies and applying.

Although this method gives excellent results with pure sinusoidal waveforms, noticeable errors appear in presence of harmonics.

\section{IV.EXPERIMENTAL SETUP}

The circuit is based on the programmable controllers (arduino) and the Wi-Fi chip. The circuit measures electrical power by measuring current and voltage using the power law (Power = voltage $\mathrm{x}$ current $\mathrm{x}$ power factor). The data is then sent to the computer via Wi-Fi, the calculation of the total consumption of the electrical loads and the calculation of the consumption tariff of the consumer capacity. Figure 6 the design phase of the circle program proteus. Figure 7 shows the circuit after development practically. The main constituency of the project consists of the following sections:

- $\quad$ Circuit calculation of voltage and current using Arduino.

- Transmitter circuit from the Arduino to the computer via the Wi-Fi network.

- $\quad$ Program to calculate the total capacity and consumption on the computer.

Table 2 shows the virtual capacity of each square meter of area for different types of use. Table 3 shows the estimated charges for common electrical appliances Program Description Calculate the power consumption of the computer Price in the Arab Republic of Egypt for 2017. Program Description Calculate the power consumption of the computer using Price in the Arab Republic of Egypt for 2017 
International Journal of Innovative Research in

Electrical, Electronics, Instrumentation and Control Engineering

Vol. 8, Issue 11, November 2020

DOI 10.17148/IJIREEICE.2020.81101

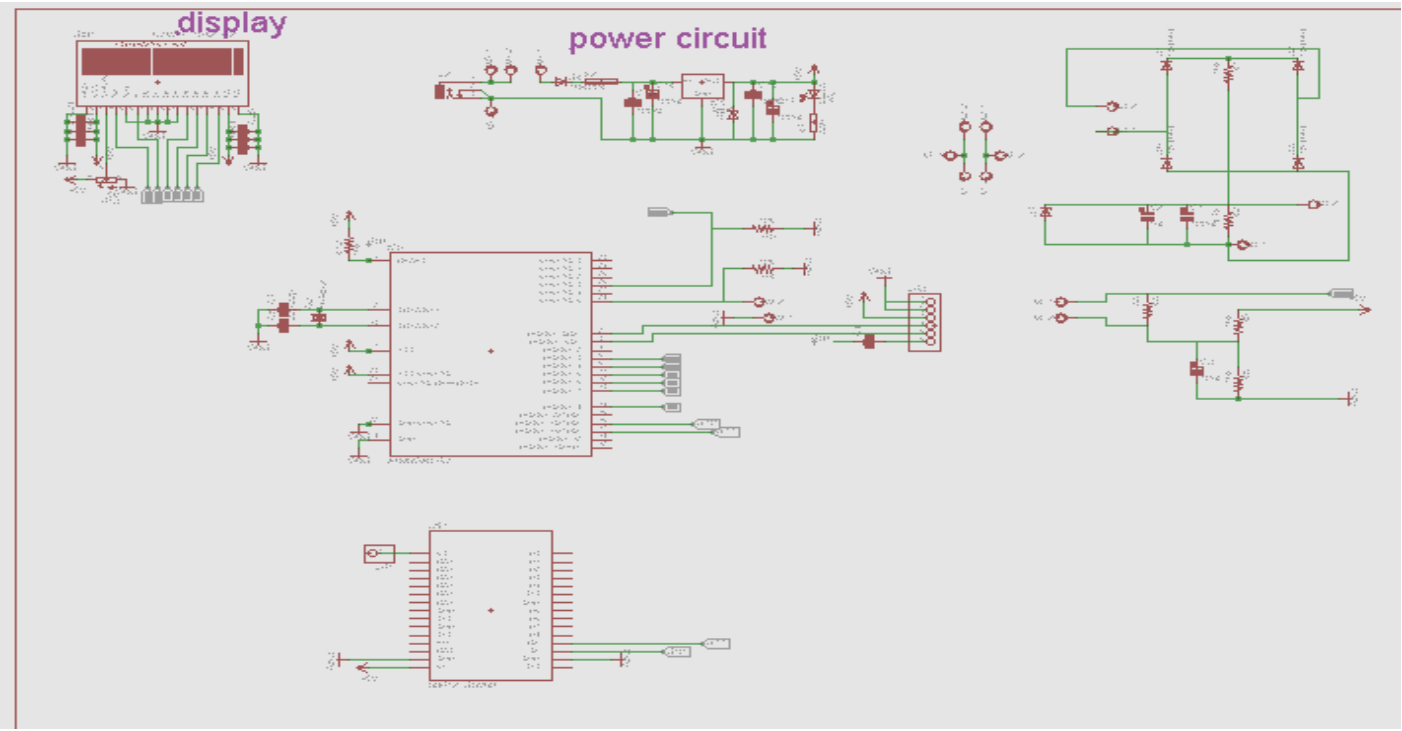

Figure 6 Execution of the circuit on the program proteus Design suite 8.5

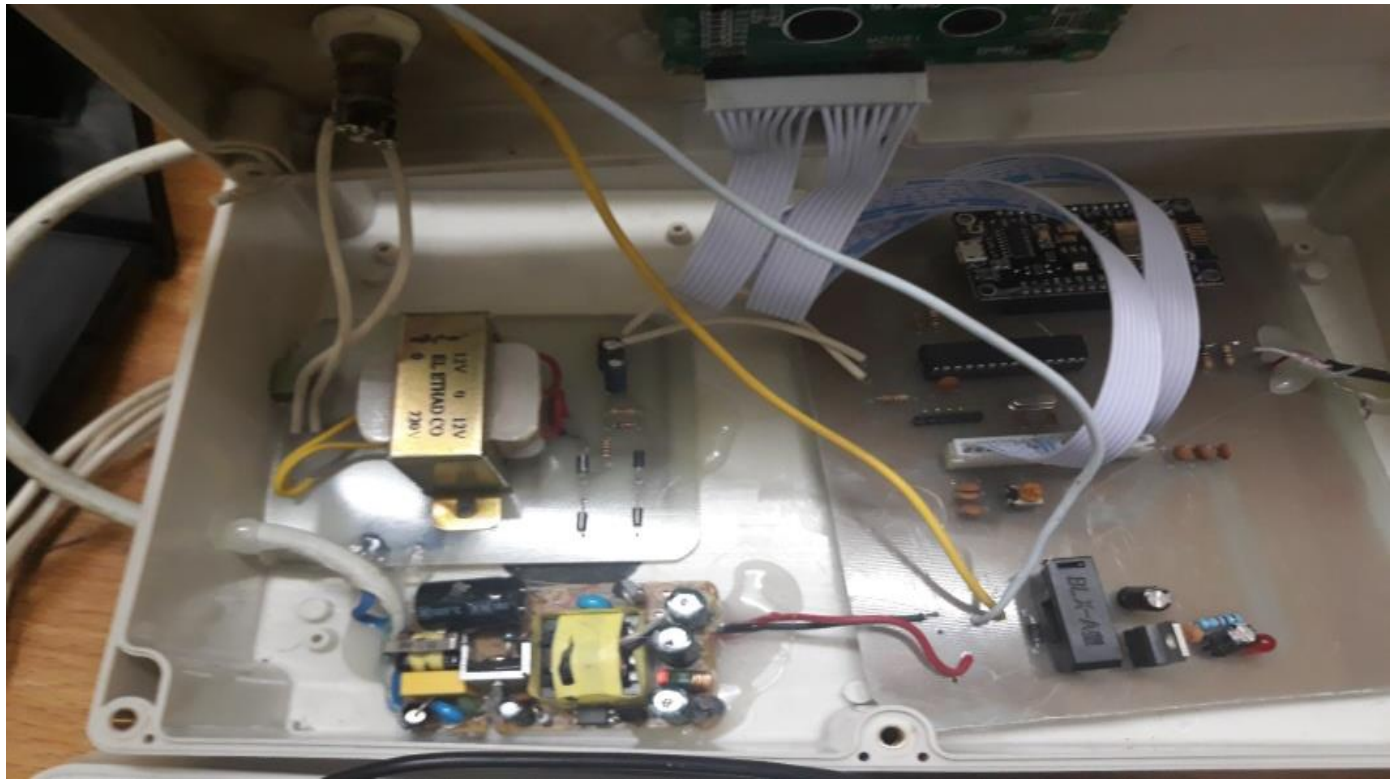

Figure 7 The executive branch of the apparatus

Table 2 the virtual capacity of each square meter of area for different types of use

\begin{tabular}{||c|c|c|c||}
\hline Capacity [W] & Monitoring device & Capacity (watts) & The device \\
\hline \hline $100-160$ & Fridge & 500 & Reddish bread \\
\hline $30-100$ & The radio & $500-1000$ & iron \\
\hline $200-300$ & TV set & 1500 & Electric cooker \\
\hline $150-300$ & Vacuum Cleaner & 500 & Hair Dryer \\
\hline 1500 & Room fire extinguisher & $2000-3000$ & Heaters 15 liters \\
\hline 300 & electric washer & $4000-6000$ & 60 liter heaters \\
\hline 6300 & With a heater & $4000-6000$ & 80 L heaters \\
\hline 100 & Laundry facilities & 700 & Water kettle \\
\hline
\end{tabular}


International Journal of Innovative Research in Electrical, Electronics, Instrumentation and Control Engineering

Vol. 8, Issue 11, November 2020

DOI 10.17148/IJIREEICE.2020.81101

Table 3 the estimated charges for common electrical appliances

\begin{tabular}{|c|c|c|}
\hline \multicolumn{1}{|c|}{ Virtual capacity [volt - ampere per square meter] } & \multicolumn{1}{|c|}{ Type of use } \\
\hline Various loads & Lighting & \\
\hline 20 & $35-45$ & Bank \\
\hline 10 & $50-60$ & Cafeteria \\
\hline 20 & $40-60$ & A place for the computer \\
\hline 15 & $50-60$ & Basement \\
\hline 10 & $40-50$ & The main floor \\
\hline 5 & $30-40$ & upstairs \\
\hline 15 & 50 & Garage \\
\hline 10 & $20-30$ & hospital \\
\hline 5 & $60-80$ & Entrances \\
\hline 5 & $15-25$ & the rooms \\
\hline 20 & $50-70$ & Office building \\
\hline & 5 & Hallways and lobby \\
\hline
\end{tabular}

\section{V.RESULTS}

There are two ways to get the results. The first is the Short-term method. It is to take the loads in place and calculate the capacity separately and collect the total capacity of all loads and the number of operating hours per load approximately) and compared with the invoice issued by the electricity company and reduce the loads of the most consumption of capacity gradually until we get the required consumption.

The disadvantages of this method depend on the possibilities of several of them:-

- $\quad$ Obtaining the total consumption of the invoice

- Calculation of consumption by approximation.

- Inaccurate operating hours for each load.

- $\quad$ Different loads from each house to the other.

- $\quad$ Reliance on general data on electrical loads

The second method is the Long-term method. The long-term method is divided into two parts:-

- Calculate the consumption of loads in the house through the electric meter and the calculation of the total consumption of the bill of Electricity Company

- $\quad$ Calculate the consumption of loads separately and the actual operating hours of each load and calculate the actual consumption of all loads (for one month) and record data and compare the total consumption with consumption from the electricity, phase (1 month)

By observing the difference between the two consumption values and reduce the actual working hours of loads over the next month and the calculation of total consumption and compared with the consumption of electricity

Second stage (month 2)

This method is done by noting the difference between the two consumption values. This method was repeated several times in a row for each month with the data recorded until we get the required consumption for the home and install the operating hours for all loads on the last data already taken.

Problems facing the study:-

-When comparing the actual consumption with the consumption of the bill issued by the electricity company and found a difference between the two values .

-When there is a small difference that is calculated from the company on the system of slides and increases the cost to the consumer >

In both cases, is there a way to adopt the results from the department

Table 4 show the tariff used in Egypt for calculating the consumption energy for each slide.

\section{Taking the results}

Short-term method:- After taking the readings from the machine and comparing them with the reading of the meter of the electric company, we found that in a big difference between the values of power consumption between the two, which are as follows:

- $\quad$ reading monthly consumption of the meter $164 \mathrm{~kW}$

- $\quad$ Read the consumption of loads during the month on the device $145 \mathrm{~kW}$

It is clear that the difference in reading up to 16 kilowatts per month with a precision of $11.6 \%$ for the device. 
International Journal of Innovative Research in

Electrical, Electronics, Instrumentation and Control Engineering

Vol. 8, Issue 11, November 2020

\section{DOI 10.17148/IJIREEICE.2020.81101}

The following table shows the data of the machine and meter reading from the electricity bill of the electricity company and a chart. Table 4 shows the value of load consumption by the household meter for February 2018 , Table 3 the value of load consumption by the performing device, Figure 8 shows the electricity bill issued by electricity company for the month of February 2018, Figure 9 shows the graph of the relationship between the resolution of the source device and read as many household during the month of February 2018.

Table 4 the Pricing for residential segments for 2018

\begin{tabular}{|c|c|}
\hline \multicolumn{2}{|c|}{ Pricing for residential segments } \\
\hline Piasters & k.W.h \\
\hline 13 & $1-50$ \\
\hline 22 & $50-100$ \\
\hline 30 & $100-200$ \\
\hline 55 & $200-300$ \\
\hline 75 & $351-650$ \\
\hline 125 & $500-1000$ \\
\hline 135 & $1000-2000$ \\
\hline 300 & More than 10,000 \\
\hline
\end{tabular}

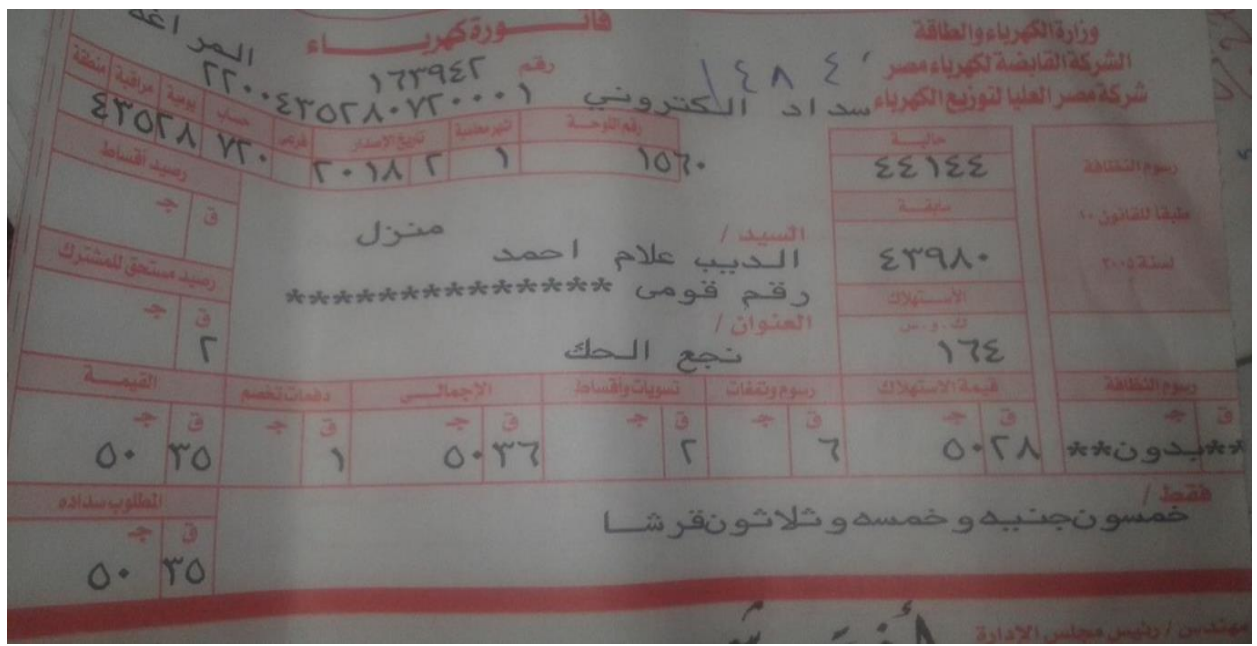

Figure 8 the electricity bill issued by the Electricity Company for the month of February 2018

Table 5 the value of load consumption by the household meter for February 2018

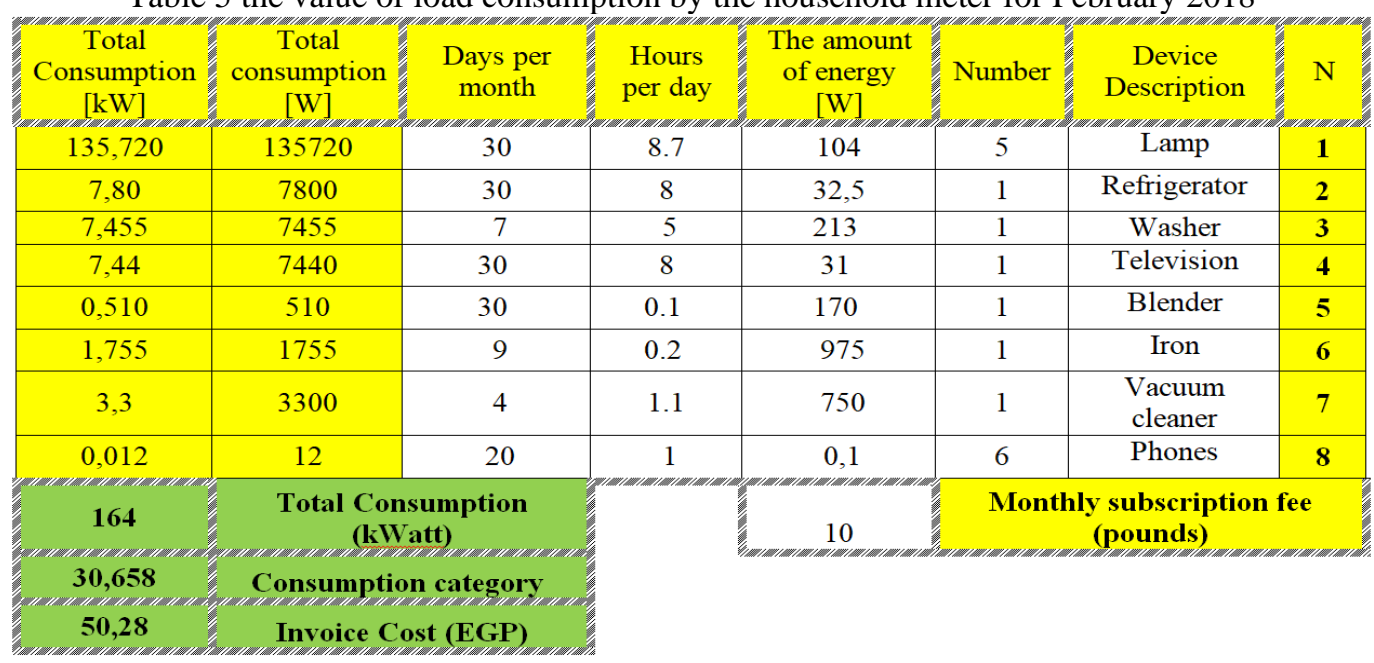


International Journal of Innovative Research in Electrical, Electronics, Instrumentation and Control Engineering

Vol. 8, Issue 11, November 2020

DOI 10.17148/IJIREEICE.2020.81101

Table 6 Load consumption using the proposed device

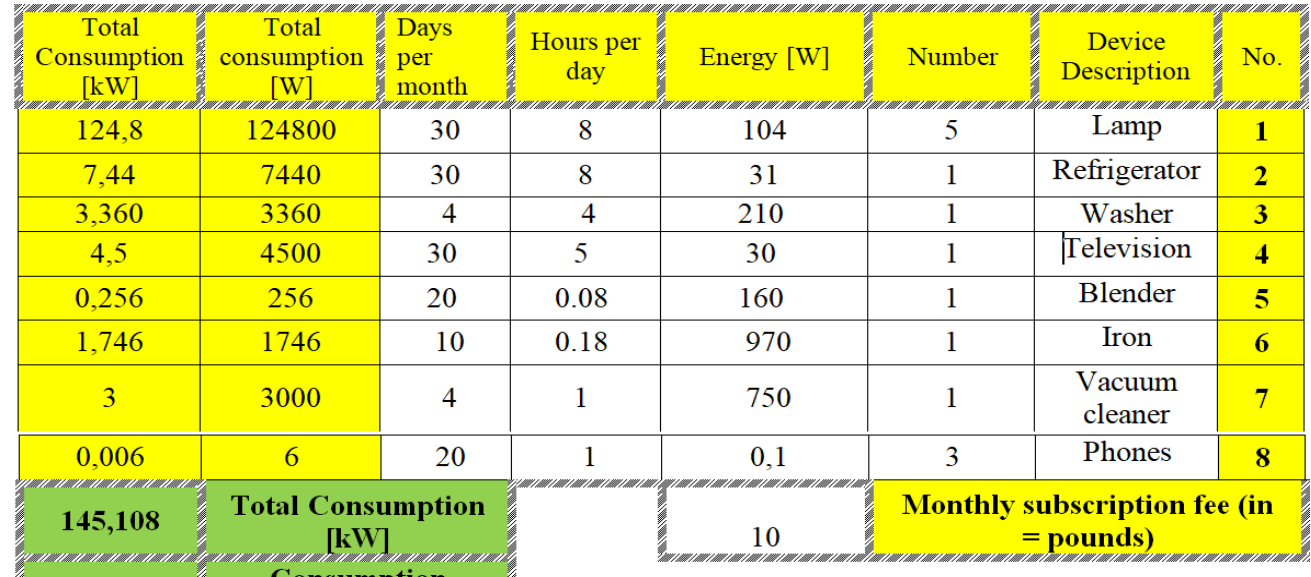

30,658 Consumption

category

44,48 Invoice Cost (EGP)

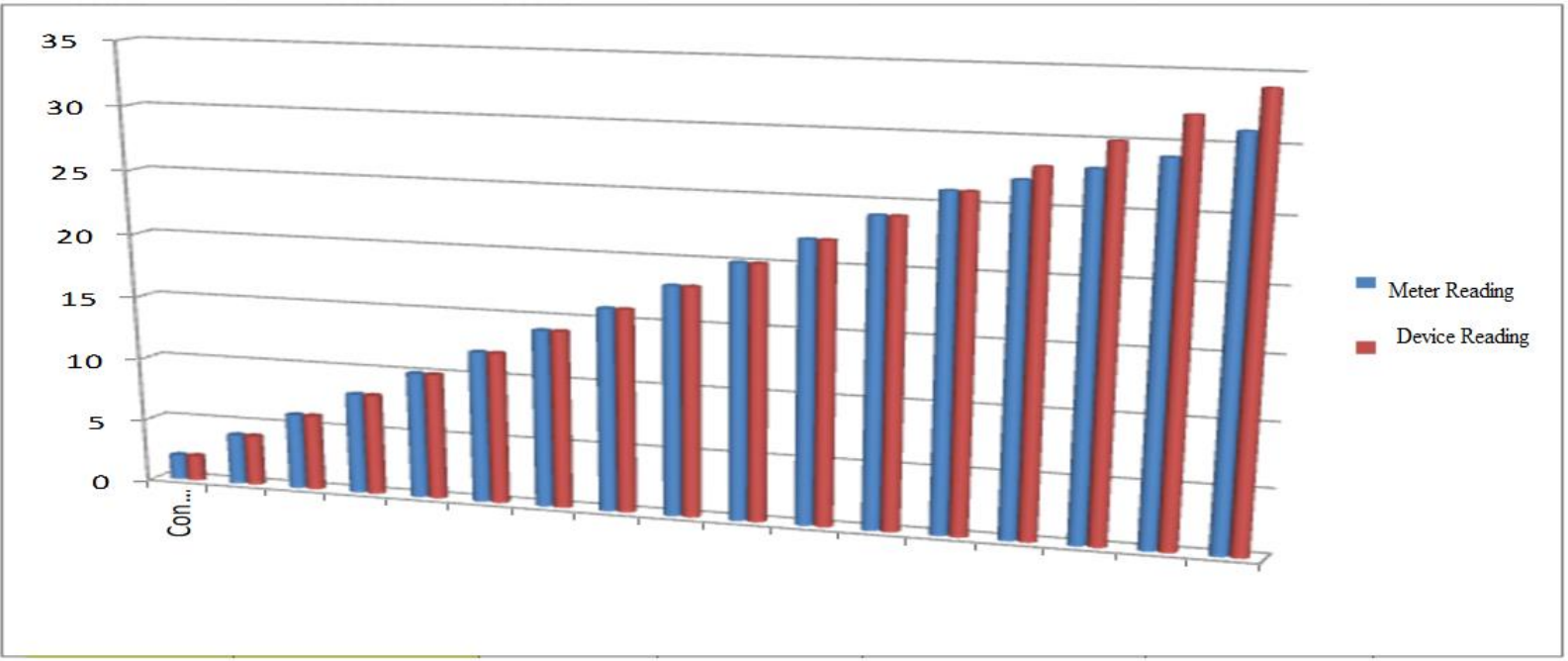

Figure 9 Comparison between reading the energy consumption by the device and the domestic meter of the electricity company for the month of February 2018

\section{Long-term method:-}

In this way, electricity consumption was rationalized by reducing the operating hours for a set of loads that affect the increase in consumption (eg, inductive loads) to match the value of the costs to be paid to the electricity company and taking into consideration the regularity of the loads in the natural situation that does not affect the work. The readings were as follows.

\section{- $\quad$ Readings meter previous month $164 \mathrm{~kW} 1$.}

- $\quad$ Readings of the meter new month $122 \mathrm{~kW}$.

The following table shows the readings this month with a picture of the electricity bill and a chart showing the difference between the two readings, Table 7 shows the value of load consumption by the household meter for March 2018, Figure 10 shows the monitoring and rationalization of electricity consumption for February and March 2018. Figure 11 shows the electricity bill issued by Upper Egypt Electricity Company for the month of March 2018. 
IJIREEICE

International Journal of Innovative Research in Electrical, Electronics, Instrumentation and Control Engineering

Vol. 8, Issue 11, November 2020

DOI 10.17148/IJIREEICE.2020.81101

Table 7 the value of load consumption by the household meter for March 2018

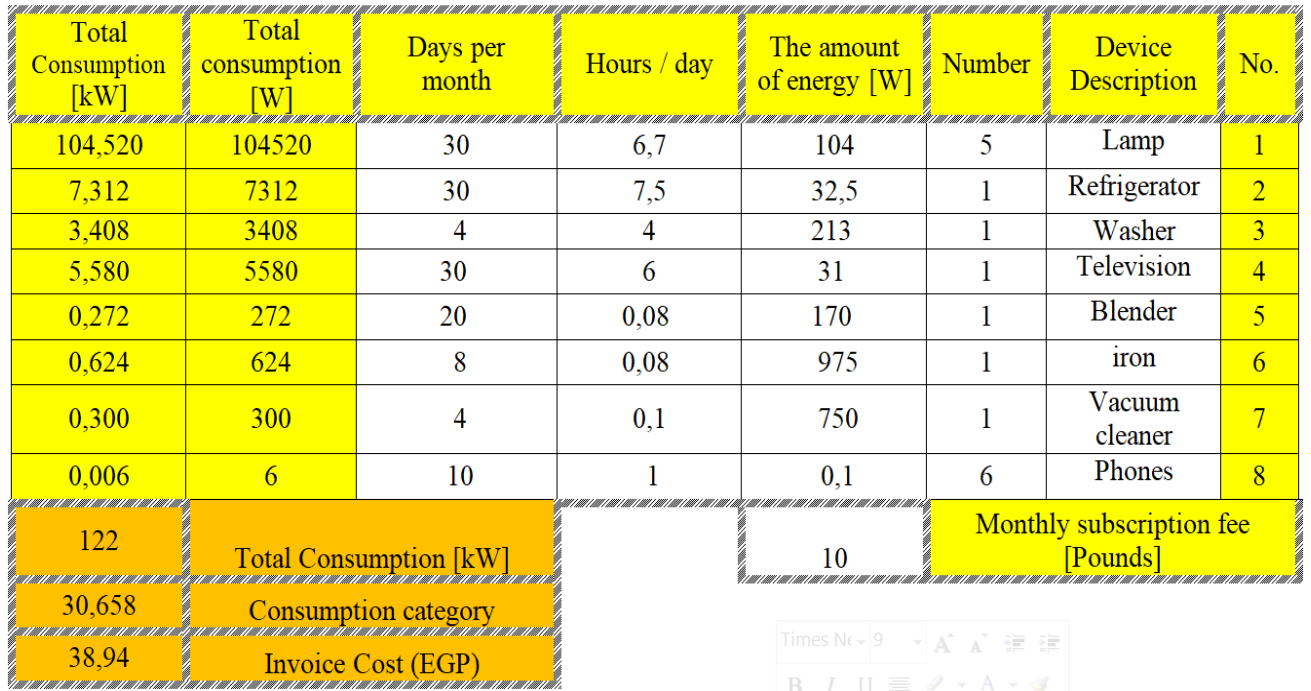

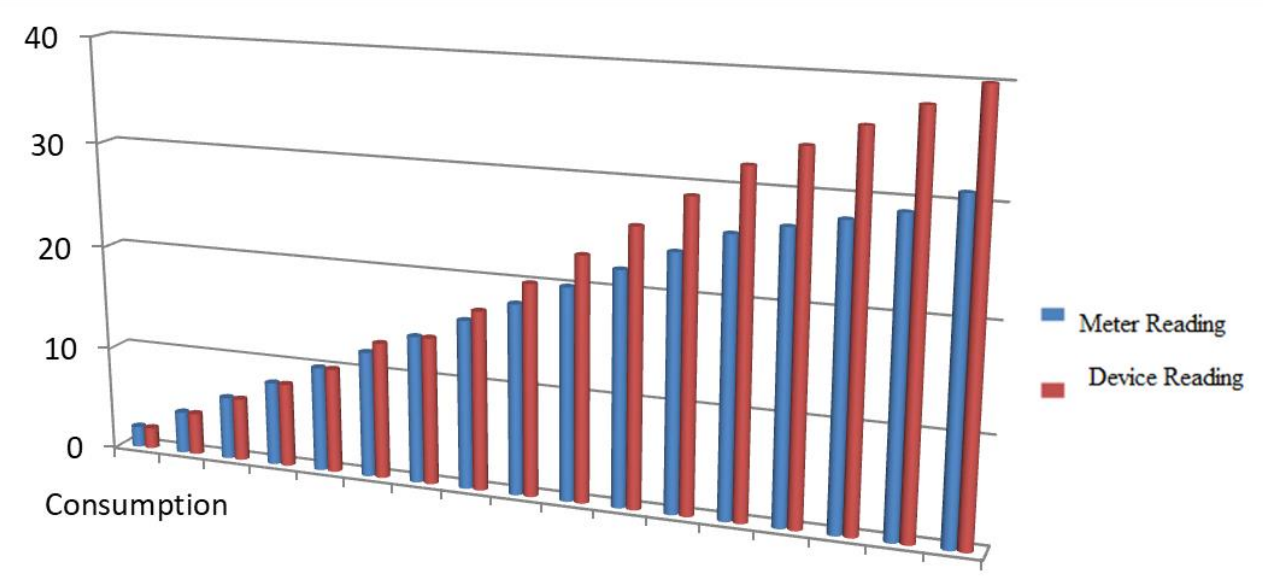

Figure 10 monitoring and rationalization of electricity consumption for February and March 2018

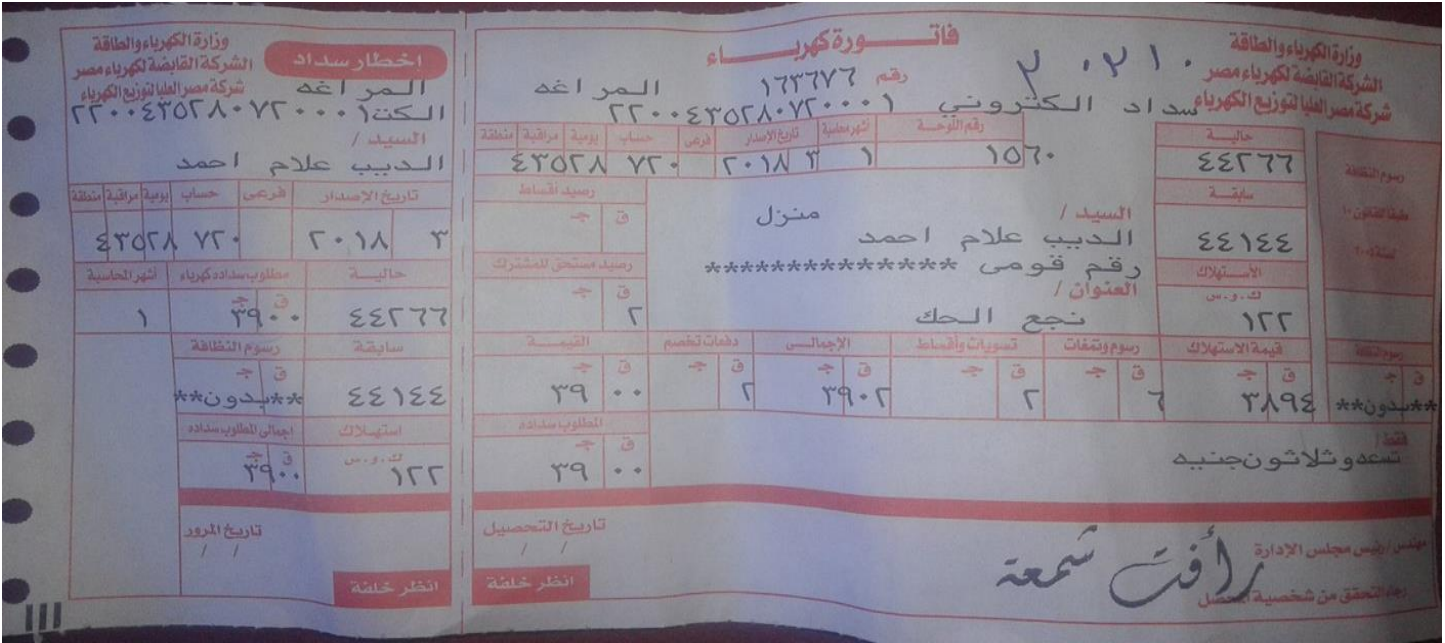

Figure 11 the electricity bill issued by the Electricity Company for the month of March 2018 


\section{International Journal of Innovative Research in Electrical, Electronics, Instrumentation and Control Engineering}

Vol. 8, Issue 11, November 2020

DOI 10.17148/IJIREEICE.2020.81101

\section{VI.DISCUSSION}

From the previous results, we obtain from the first method, the rate of energy conservation is up to $11 \%$. In the second method, we reach the rate of rationalization of consumption up to $26 \%$ of the total energy consumption, and we can combine the two methods together so that the consumption and rationalization is monitored using the implemented model instead of the home meter. Rationalization of consumption of the second method depending on the reading of the device instead of the home counter to obtain the accuracy of the control of the consumption of loads and rationalization may reach $40 \%$ of the total consumption of the house, The diagram below shows the relationship between the three methods as shown in Figure 12.

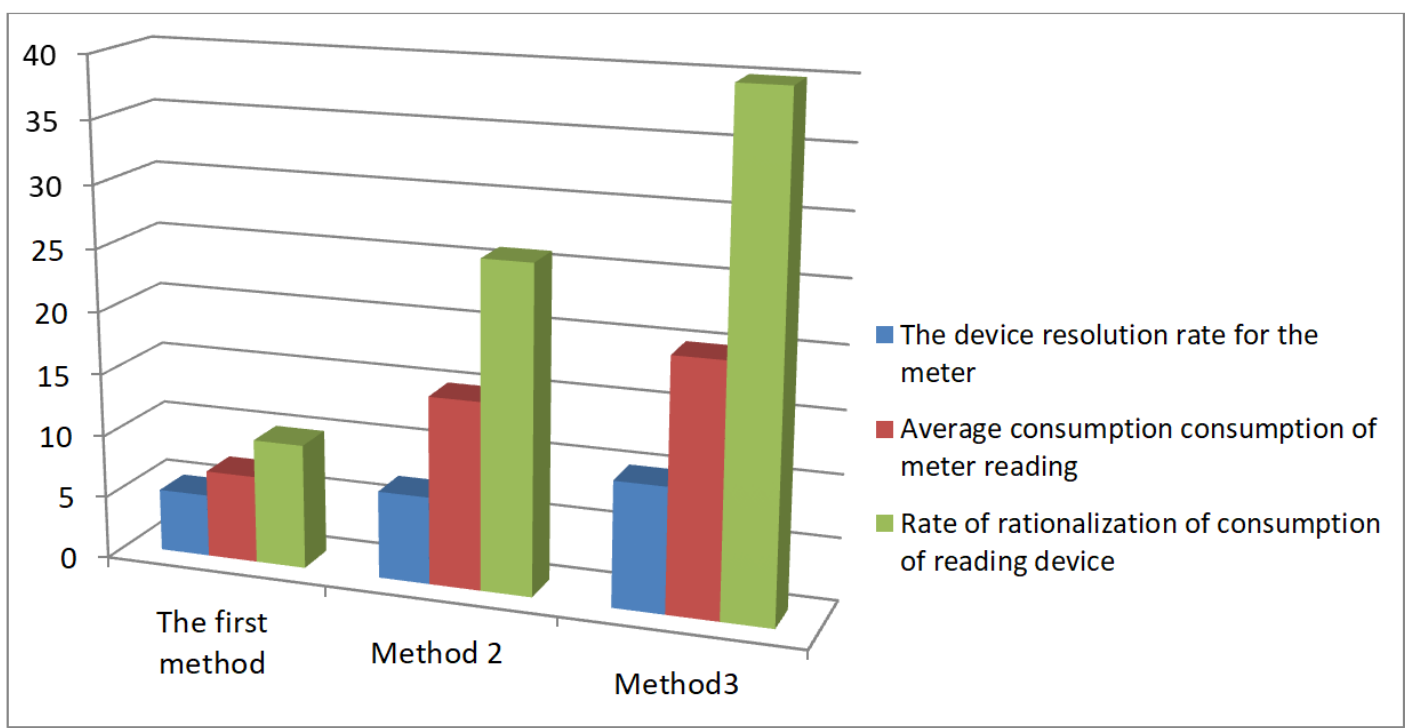

Figure 12 The relationship between rationalization of electric power consumption using machine reading and home meter readings

\section{VII.CONCLUSIONS}

From the above, in terms of studying the previous results, it is clear to us that the extent of control and rationalization of energy consumption by the device with the household meter of the electricity company exceeded the rationalization rate from 10 to $26 \%$ reduction in energy for the consumer. The use of the device only alternative home counter exceeded the rationalization rate from 30 to $40 \%$ Decrease in energy for the benefit of the consumer, because the accuracy of the device in the control of electric energy from the household meter of the electricity company exceeded $10 \%$, so we propose in this research to replace the home meter of this device for the accuracy of measurement and control of electric energy. The programmable type controllers (Arduino) collects data and send it with high accuracy to the internet networks (Wi-Fi). The total system is implemented using a smaller size and cheaper price of components. The benefit from the control of electricity and rationalization of electricity is verified for both the consumer and electricity companies. The approach of visualizing information will encourage users to be more aware of their energy consumption needs.

\section{REFERENCES}

[1]. Helen Ai He, Saul Greenberg, " Motivating Sustainable Energy Consumption in the Home" prism , University of Calgary CA, 2008.

[2]. M Marcu , C Stangaciu, A Topirceanu, D Volcinschi, and V Stangaciu ,"Wireless Sensors Solution for Energy Monitoring, Analyzing, Controlling and Predicting ", conference on sensor , springer, 2010.

[3]. J G Josué, J M. Pina, and M V Neves "Home Electric Energy Monitoring System , Design and Prototyping" IFIP AICT 349, pp 437-444, 2011.

[4]. A M Marcia, R B Ortega, I D F lava, P A vila, F F gil " A power consumption monitoring, displaying and evaluation system for home devices" Waves, ISSN 1889-8297, riunet.upv.es, 2013.

[5]. Srividyadevi P., Pusphalatha D . V .and Sharma P.M ,"Measurement of power and Energy Using Arduino", Res. J . Engineering sci.2(10) 1015., pp October-2013,ISSN 2278-9472, 2013.

[6]. Mendes, T.D.P.; Godina, R.; Rodrigues, E.M.G.; Matias, J.C.O.; Catalão, J.P.S. Smart Home Communication Technologies and Applications: Wireless Protocol Assessment for Home Area Network Resources. Energies 2015, 8, 7279-7311.

[7]. Paolo Visconti, Patrizio Primiceri, and Georgio Cavalera, " Wireless Monitoring System of Household Electrical Consumption with DALYbased Control Unit of Lighting Facilities Remotely Controlled by Internet" h rcak. Srcee.hr, Vol. 12, No. 1, 2016.

[8]. P. Visconti, A. Lay-Ekuakille, P. Primiceri, and G. Cavalera , "Wireless smart system for monitoring and driving of household electrical facilities remotely controlled by Internet" IEEE, 2016. 


\title{
International Journal of Innovative Research in Electrical, Electronics, Instrumentation and Control Engineering
}

\author{
Vol. 8, Issue 11, November 2020
}

DOI 10.17148/IJIREEICE.2020.81101

[9]. EMG Rodrigues, T Caramelo, TDP Mendes, R Godina,and JPS Catalão , "Experimental Wireless Wattmeter for Home Energy Management Systems" Doctoral conference ,Springer, 2015.

[10]. M.Indhumathi , T.Devakumar, June, "Design and Implementation of I O T based Digital Energy Meter for Remote Monitoring ", International Journal For Trends In Engineering \& Technology Volume 14, Issue 1, Pp. June-2016, ISSN 2349- $9303,2016$.

[11]. Zaid Abdulzahra Jabbar1, R.S. Kawitkar2, February, "Implementation of Smart Home Control by Using Low Cost Arduino \& Android Design", International Journal of Advanced Research in Computer and Communication Engineering vol. 5 issue 2, 2016, ISSN 2278-1021, 2016 .

[12]. Vaishnavi S. Gunge, Pratibha S. Yalagi, "Smart Home Automation: A Literature Review ", International Journal of Computer Applications (0975 - 8887), National Seminar on Recent Trends in Data Mining , 2016.

[13]. R.Bhavani and S.Alagammal , "Design And Implementation Of Gsm Based Smart Energy Meter (Sem) For Home Applications , International Journal of Latest Trends in Engineering and Technology, Vol. 8, No. 1, 2016 .

[14]. Samarth Pandit, SnehaMandhre, Meghana Nichal, "Smart Energy Meter using internet of Things (IoT)" , VJER-Vishwakarma Journal of Engineering Research, Volume 1 ISSN 2456-8465,2017.

[15]. Parker, Danny, Hoak,David, Meier, Alan, \& Brown, Richard ,"How Much Energy Are We Using? Potential of Residential Energy Demand Feedback Devices" Florida Solar Energy Center/University of Central Florida, 2008.

[16]. Dobson, JK and JDA Griffin , " Conservation Effect of Immediate Electricity Cost Feedback on Residential Consumption Behaviour", Proceedings, American Council for an Energy-Efficient Economy, 10.33-10.35,1992.

[17]. Mansouri, I and Newborough, M , "Dynamics of Energy Use in the UK Households: End-Use Monitoring of Electric Cookers. Proceedings, European Council for an Energy-Efficient Economy", Panel III, 08 , 1999.

[18]. Wisam Nader ,"Real-Time Power Monitoring, Home Automation And Sustainability", Master thesis, University of Nebraska-Lincoln, 2011.

[19]. Zeya Zheng, "Home Automation, Smart home technology and template house design", Savonia University of applied sciences, 2013.

[20]. SatuMarttila , "Home Automation - A Challenge forElectrical Designers, Contractors and Electricians", helsinki university of technology, 200921 - Don Wilcher ,"Learn Electronics with Arduino", illustrated Edition, Apress ,2012.

[21]. Sayed, K.; Abo-Khalil, A.G.; S. Alghamdi, A. Optimum Resilient Operation and Control DC Microgrid Based Electric Vehicles Charging Station Powered by Renewable Energy Sources. Energies 2019, 12, 4240.

[22]. Sayed, K.; Gabbar, H.A. Electric Vehicle to Power Grid Integration Using Three-Phase Three-Level AC/DC Converter and PI-Fuzzy Controller. Energies 2016, 9, 532.

[23]. R. Kassem, K. Sayed, A. Kassem and R. Mostafa, "Power optimisation scheme of induction motor using FLC for electric vehicle," in IET Electrical Systems in Transportation, vol. 10, no. 3, pp. 301-309, 9 2020, doi: 10.1049/iet-est.2019.0151.

[24]. K. Sayed, "ZVS Soft-Switched DC-DC Converter based Charger for Low Voltage battery in Hybrid Electric Vehicles", IET Power Electronics, Vol. 12 , pp. 3389-3396, 2019.

[25]. Hedra Saleeb, Khairy Sayed, Ahmed Kassem, Ramadan Mostafa "Power Management Strategy for Battery Electric Vehicles", IET Electrical Systems in Transportation, Vol. 9, No. 2, pp. 65 - 74, 2019.

[26]. Mazen Abdel-Salam, Rashad Kamel, Khairy Sayed, Mohsen Khalaf, " Design and Implementation of a Multifunction DSP-based-Numerical Relay", Electric Power Systems Research, 143 (2017) 32-43.

[27]. Khairy Sayed and Hossam A. Gabbar, "Supervisory Control of a Resilient DC Microgrid for Commercial Buildings", Int. J. Process system Engineering, Vol. 4, No. 2-3, pp. 99-118, 2017.

[28]. Arduino uno . https://www.arduino.cc, 2017.

[29]. A-ESP8266-Data sheet - EN-v4.3 . http ://bbs.espressif.com , 2015

[30]. Specifications of LCD module - data sheet, 2008.

[31]. K. Sayed, A. M. Kassem, I. Aboelhassan, A. M. Aly and A. G. Abo-Khalil, "Energy Management and Control Strategy of DC Microgrid Including Multiple Energy Storage Systems," 2019 21 st International Middle East Power Systems Conference (MEPCON), Cairo, Egypt, 2019, pp. 736-741, doi: 10.1109/MEPCON47431.2019.9008076.

[32]. A. Elnozahy, K. Sayed and M. Bahyeldin, "Artificial Neural Network Based Fault Classification and Location for Transmission Lines," 2019 IEEE Conference on Power Electronics and Renewable Energy (CPERE), Aswan City, Egypt, 2019, pp. 140-144, doi: 10.1109/CPERE45374.2019.8980173.

[33]. H. A. Gabbar and K. Sayed, "Smart distribution system Volt/VAR control using the intelligence of smart transformer," 2016 IEEE Smart Energy Grid Engineering (SEGE), Oshawa, ON, 2016, pp. 52-56, doi: 10.1109/SEGE.2016.7589499.

[34]. Praveen R.P. ; Jose Therattil ; Jenson Jose ; Ahmed Abo-Khalil ; Ali Alghamdi ; G.R Bindu ; Khairy Sayed, "Hybrid Control of a Multi Area Multi Machine Power System with FACTS Devices using Non-linear Modelling", IET Generation, Transmission \& Distribution, Vol. 14 , No. 10 , pp. $1993-2003,2020$.

[35]. A. M. Aly, A. M. Kassem, K. Sayed and I. Aboelhassan, "Design of Microgrid with Flywheel Energy Storage System Using HOMER Software for Case Study," 2019 International Conference on Innovative Trends in Computer Engineering (ITCE), Aswan, Egypt, 2019, pp. 485-491, doi: 10.1109/ITCE.2019.8646441. 